Article

\title{
Development and Validation of the Career Adaptability Scale for Undergraduates in Korea
}

\author{
Jihyo Kim
}

check for

updates

Citation: Kim, J. Development and Validation of the Career Adaptability Scale for Undergraduates in Korea. Sustainability 2021, 13, 11004. https:// doi.org/10.3390/su131911004

Academic Editor: Betina Silva Lopes

Received: 23 August 2021

Accepted: 29 September 2021

Published: 4 October 2021

Publisher's Note: MDPI stays neutral with regard to jurisdictional claims in published maps and institutional affiliations.

Copyright: (C) 2021 by the author. Licensee MDPI, Basel, Switzerland. This article is an open access article distributed under the terms and conditions of the Creative Commons Attribution (CC BY) license (https:/ / creativecommons.org/licenses/by/ $4.0 /)$.
Department of Career, College of Liberal Arts, Dankook University, Cheonan 31116, Korea; jihyokim@dankook.ac.kr; Tel.: +82-41-550-1574

\begin{abstract}
This study explores factors of career adaptability and develops a measurement scale for undergraduates in Korea. The scale measuring the undergraduates' career adaptability consists of nine factors across three areas, as follows: knowledge and recognition for the self and work environment (self-understanding to establish identity, search for work environment, positive career beliefs), self-directed coping related to career behavior (coping with career-choice crisis, career preparation behavior, ability to coordinate career goals), environmental interactions for career decision and adaptation (ability to cope with environmental stress, social responsibility, ability to utilize social resources). First, an item analysis using the Rasch model was conducted, and measurement values of the items were compared. Second, an exploratory factor analysis and confirmatory factor analysis, applying the structural equation model, were performed. Third, Cronbach's alpha was calculated to establish the reliability of the scale. The Rasch model fit analysis, to measure validity, revealed that 44 items were valid. The aforementioned model, consisting of nine factors across three areas, was shown to be suitable by the confirmatory factor analysis. The results of this study help in the development of career education programs by clarifying factors of career adaptability and providing information about differences based on the factors.
\end{abstract}

Keywords: career adaptability; scale; undergraduates; Rasch model; structural equation model

\section{Introduction}

The ability to adapt is essential to survive and thrive in a rapidly changing world of work and other facets of life. This ever-changing world does not guarantee security, and influences the roles and timing in an individual's career path and various areas of life. As the roles required in individual career paths become diversified, stability in one's career may no longer be an advantage. It is necessary to pay attention to career adaptability, which plays an important role in dealing with continuous career transitions and changes [1].

Career adaptability has frequently been cited as an essential ability for successful career development that helps cope with numerous challenges in careers and workplaces [2,3]. It is the ability to cultivate and utilize psychological and social resources that are necessary to transform oneself and one's situation for satisfaction and success at work [4]. The focus of recent studies on career adaptability has expanded from successful employment to how individuals respond to job changes, how they interact with society, and how they build their careers and adapt [5]. With the growth of the concept of career development, research on this issue has been actively conducted on various participants in career fields.

The concept of career adaptability [6] began with the concept of career maturity presented in the career development theory by Super. It was embodied through the career construct theory (CCT; $[5,7,8])$. The term "career adaptability" is studied in various aspects, such as personality characteristics, social ability, and behavior, which may cause conceptual confusion. Therefore, Savickas et al. [9] subdivided career adaptability into adaptation processes by proposing a career adaptation model. The theoretical framework of sequential processes consists of adaptivity, adaptability, adapting, and adaptation [10]. Adaptivity 
refers to attitude, belief, and competence, reflecting readiness and propensity for career adaptability. Adaptability refers to resources for adapting and consists of concern, control, curiosity, and confidence about one's career. Adapting refers to actions taken in response to the changing environment and includes planning, exploration, decision making, and implementation. These adapting actions lead to adaptation, such as successful career development [8]. When there is an adaptive problem in one's career path and work, it provides a baseline for distinguishing whether it falls in the personal traits domain, competence domain, resource domain, or behavior domain, through which appropriate intervention measures can be derived. Particularly, adaptability, adaptive competence, and psychological/social resources can be improved through education and training, unlike individuals' inherent traits.

Savickas and Pofeli [10] developed and validated the career adapt-abilities scale (CAAS) for appropriate educational intervention to improve career adaptability. Several tools, including the CAAS, have been developed to measure the career adaptability of university students [10-12], and have been used in various studies. However, it seems necessary to develop a scale supplementing the following points. First, a career adaptability scale should be developed according to career development challenges, considering the cultural background of South Korean university students. The CAAS is intended to be valid in a broad cultural context [9]. However, it is necessary to examine whether this scale includes attributes of adaptability resources that are required to perform career development tasks appropriately, in adolescence and early adulthood, in South Korea. Career development tasks change while being closely related to the environmental context to which an individual belongs, and the content of the development task to be achieved is determined through interaction with this environment [13]. In particular, South Korean students focus on their studies for most of their middle and high school years to prepare for university entrance exams. Thus, career development tasks that should have already been completed, realistically start after entering university. This results in urgency for career development during the students' undergraduate years and a lack of time for sufficiently exploring careers. Thus, students experience difficulties and sometimes extreme stress when performing tasks for systematic career development. Students need to not only develop competence for deciding on a career path through career exploration and achieving career goals, but also cultivate the ability to smoothly transition into and deal with events of the professional world. It is worth examining various adaptive factors that are required by South Korean university students to perform career development tasks that reflect these cultural and social environments.

Second, studies should be conducted to categorize sub-factors of career adaptability, considering its multi-dimensionality, and to investigate them empirically. The Career Future Inventory (CFI) [12] was developed to measure the career-related adaptability of college students. Choi and Kim [13] validated it for South Korean university students. This scale consists of ten items, including "I will adapt to the new work environment well". However, because of the career adaptability factors in a single structure, it is hard to clearly identify parts where they experience difficulties related to adaptation. Hence, Jang and Kim [11] developed a career adaptability scale to predict successful jobs for undergraduate students after their transition to professional roles. This study is meaningful as undergraduate career guidance was not limited to the graduation and employment of students, but also helped them find interest and responsibility in continuous and stable career development, even after their employment. However, it is necessary to determine the sub-factors by considering the multi-dimensional nature of career adaptability [11]. Therefore, this study will examine the structure of sub-factors based on categories to validate the hypothesis of the multi-dimensional construct of career adaptability.

Third, a scale is required to measure the competence of adapting to career paths through interactions between an individual and the world. Savickas and Porfeli [10] defined career adaptability as psychological resources interacting with the environment for successful adaptation when an individual faces expected or unexpected career development 
tasks, occupational transition, and work-related traumas in the changing professional world. How social capital is utilized and interacted with is an important factor in career adaptability, to cope with individuals' career path problems. Hence, Nota et al. [14] developed the career and work adaptability questionnaire (CWAQ) by adding a cooperation factor, such as assertive abilities and propensity to take on social responsibilities, in the CAAS. They showed that five factors are valid to measure the level of career adaptability of adolescents to cope with future plans, as new scales of career and work adaptability. Furthermore, some studies have reported that social support has a positive effect on career adaptability $[15,16]$, which implies that the career adaptability level may vary depending on how the individual interacts with the world. Therefore, interaction factors between the individual and environment will be considered as attributes of career adaptability to broaden the understanding of career adaptation behavior.

The specific research aims in this study are as follows: (1) to develop a career adaptability scale for undergraduates in Korea; and (2) to conduct validity and reliability tests on the developed scale. By elaborating on the factors of career adaptability of undergraduates in Korea, this study provides a theoretical and empirical basis for conducting future in-depth studies on career adaptability.

\section{Theoretical Background}

\subsection{Career Adaptability and Its Definitions}

Studies on adaptability have been conducted to describe one's process of adapting to survive and thrive in all areas of human life. The concept of adaptability in the fields of career and work has been used as a psychological and social resource that is necessary to adapt to situations for vocational satisfaction and success. Various scholars [5,6,10-12,14,16-19] have produced their own definitions of career adaptability.

The concept of career adaptability emerged due to its emphasis on the interaction between an individual and the environment, for adults who inevitably experience career transitions in future career fields, compared to a career maturity concept [1,5,20-22]. For the past 40 years, conceptual and empirical studies on career adaptability have been actively conducted on various subjects in organizational and human resource studies. Super and Knasel [6] first introduced the term and defined it as "the readiness to cope with the demands of the ever-changing vocational world and environment". Pratzner and Ashley [18], who argued that the concept should be extended from a position of compliance with the environment to the ability to change the environment, defined it as "the ability of individuals to not only adjust and adapt to the changes of the exterior environment, but to change the environment in accordance with one's own changes". Goodman [17], who emphasized harmony between individuals and their work environment, focused on the balance between individuals' environments and the vocational world, and defined career adaptability as "preparing to respond to predictable and unpredictable tasks during the process of preparing for roles related to work". Rottinghaus et al. [12] defined it as "the ability to cope with and utilize future changes, the level of being comfortable with new responsibilities, and the resilience to recover when one's career path is changed by unforeseen events". In addition, Nota et al. [14] defined it as "the tendency to properly address developmental tasks such as being prepared to adapt to unforeseen demands that may arise from the changes in the job market and working environment".

Savickas [5], who conceptualized career adaptability based on CCT, saw development as an adaptive process to the environment rather than personal internal growth, in terms of contextualism, in which individuals construct their own reality. Savickas [5] defined it as "resources to cope with current and future vocational developmental tasks, job performance, and personal events, and psychological and social components such as individual readiness". In a subsequent study exploring the validity and reliability of career adaptability measures, Savickas and Porfeli [10] defined career adaptability as "an individual's psychological resource to adapt to unexpected demands from the changes in the labor market and job environment, and to deal with given developmental tasks". 
Through career adaptability, individuals are connected to society, and they expand and shape themselves in a social environment by controlling their work behavior [8].

In a validation study of CFI, Choi and Kim [13] stated that career adaptability is "the ability of an individual to deal with future changes and use the changes in a positive way; the level of comfort with new job responsibilities; and the ability to recover when unexpected events change career plans". Jang and Kim [11], who conducted a career adaptability scale development study on South Korean undergraduates, defined career adaptability as "the attitude, ability, and readiness to adapt successfully to various career transitions that occur throughout one's lifetime". They claim that with higher career adaptability, individuals are more likely to achieve a successful career transition through the control of oneself and the environment. They argue that the state of adaptation after the transition and post-adaptation changes are predictable.

\subsection{Previous Studies on Sub-Factors of Career Adaptability}

This section will examine sub-factors comprised from conventional career adaptation measurement tools. Table 1 summarizes sub-factors of the domestic and international career adaptability scales.

Savickas and Porfeli [23] revised the existing Career Maturity Inventory (CMI), and developed a reliable and reasonable scale to measure the readiness of the career choice of students. The four sub-factors that measure career choice readiness are "concern, curiosity, and confidence", which reflect career adaptability, and "consultation", which reflects career choice.

The CAAS, developed by Savickas and Porfeli [10], is the most widely used scale-the validity of the scale has been verified by researchers from 13 countries. The scale consists of four sub-factors, each consisting of six items. The four sub-factors, concern, control, curiosity, and confidence, comprise psychological resources that control job transition, career developmental tasks, and difficulties encountered at work. Tak's [19] study is significant in that he explained the Korean version of CAAS [10], and demonstrated that the scale with four sub-factors is a theoretical model and a multidimensional hierarchy of career adaptability with high internal consistency. It can be utilized by researchers and practitioners to measure the career adaptability of South Korean students.

Maggiori et al. [24] developed and validated the CAAS short form (CAAS-SF), a simple version of the CAAS [10]. They developed items to measure sub-factors of CAAS, such as concern, control, curiosity, and confidence. It is significant that they have developed an economical scale in place of the CAAS, by revealing the high association between the CAAS-SF and CAAS.

Nota et al. [14] developed the CWAQ to assess adaptability, to lead professional lives and prepare for the future in the rapidly changing job market. The scale consists of the following five sub-factors: concern, control, curiosity, confidence, and cooperation. They confirmed the multidimensional structure of the scale and verified its validity.

Rottinghaus et al. [25] developed the CFI to measure career optimism and career adaptability, which has the following three sub-factors: career adaptability, career optimism, and perceived knowledge. Rottinghaus et al. [26] developed the CFI-R, the revised version of CFI, which consists of career agency, occupational awareness, support, work-life balance, and negative career outlook related to career adaptability, positive career planning attitude, and future expectations. The CFI-R measures career agency, where self-awareness, control, and performance management are related to self-efficacy.

Pulakos et al. [27] developed a classification system of adaptive task performance and conducted research to understand, predict, and train adaptive behavior in the work environment. The eight sub-factors of adaptive task performance are handling emergencies or crisis situations; handling work stress; solving problems creatively; dealing with uncertain and predictable work situations; learning work tasks, technologies, and procedures; interpersonal adaptability; cultural adaptability; and physically oriented adaptability. 
Zhang et al. [28] developed and validated a tool to measure the career adaptability of Chinese soldiers. The measured sub-factors of career adaptability are organization and fusion ability, communication ability, learning development ability, emotional control ability, and career transformation ability.

Jang and Kim [11], in their career adaptability scale for South Korean students, suggested personal relations, sense of purpose, creativity, responsibility, job performance, positive attitude, self-directedness, and openness as sub-factors of the scale.

Table 1. Sub-factors of prior studies on career adaptability.

\begin{tabular}{|c|c|c|c|c|c|c|c|}
\hline Sub-Factors & (1) a & $(2) b$ & (3) $\mathrm{c}$ & (4) d & (5) e & (6) $f$ & (7) $\mathrm{g}$ \\
\hline Concern & 1 & 1 & 1 & - & - & - & - \\
\hline Control & & 1 & 1 & - & - & - & - \\
\hline Curiosity & 1 & 1 & 1 & - & - & - & - \\
\hline Confidence & 1 & 1 & 1 & - & - & - & - \\
\hline Cooperation & - & - & 1 & - & - & - & - \\
\hline Consultation & 1 & - & - & - & - & - & - \\
\hline Career agency & - & - & - & 1 & - & - & - \\
\hline Occupational awareness & - & - & - & 1 & - & - & - \\
\hline Support & - & - & - & 1 & - & - & - \\
\hline Work-life balance & - & - & - & 1 & - & - & - \\
\hline Negative career outlook & - & - & - & 1 & - & - & - \\
\hline Handling emergencies or crisis situations & - & - & - & - & 1 & - & - \\
\hline Handling work stress & - & - & - & - & 1 & - & - \\
\hline Solving problems creatively & - & - & - & - & 1 & - & - \\
\hline Dealing with uncertain and unpredictable work situations & - & - & - & - & 1 & - & - \\
\hline Learning work tasks, technologies, and procedures & - & - & - & - & 1 & - & - \\
\hline Interpersonal adaptability & - & - & - & - & 1 & - & - \\
\hline Cultural adaptability & - & - & - & - & 1 & - & - \\
\hline Physically oriented adaptability & - & - & - & - & 1 & - & - \\
\hline Organization and fusion ability & - & - & - & - & - & 1 & - \\
\hline Communication ability & - & - & - & - & - & 1 & - \\
\hline Learning development ability & - & - & - & - & - & 1 & - \\
\hline Emotion regulation ability & - & - & - & - & - & 1 & - \\
\hline Career transformation ability & - & - & - & - & - & 1 & - \\
\hline Personal relations & - & - & - & - & - & - & 1 \\
\hline Sense of purpose & - & - & - & - & - & - & 1 \\
\hline Creativity & - & - & - & - & - & - & 1 \\
\hline Responsibility & - & - & - & - & - & - & 1 \\
\hline Job performance & - & - & - & - & - & - & 1 \\
\hline Positive attitude & - & - & - & - & - & - & 1 \\
\hline Self-directedness & - & - & - & - & - & - & 1 \\
\hline Openness & - & - & - & - & - & - & 1 \\
\hline
\end{tabular}




\subsection{Career Development Tasks of Undergraduate Students}

According to the career development theory, undergraduate years are an important period to accomplish various developmental tasks. Developmental tasks refer to those that must be accomplished in a certain developmental stage, i.e., tasks that must be completed in a certain period of life [29]. Undergraduate years are a transition period from adolescence to adulthood, in which students should take responsibility as independent individuals. Particularly, South Korean university students perform various developmental tasks as soon as they enter university, such as self-reflection, career exploration, career decision, and career preparation, which are significant in that they have an important impact on future career success and employment.

Ginzberg [30] classified the following three career development stages: fantasy, tentative, and realistic. University students are in the realistic stage, which comprises of the following three sub-stages: the exploration stage (careers of interest are explored), the crystallization stage (the career goal is set, and factors related to the occupational choice and career decision are crystallized), and the specification stage (more detailed plans are made for their decisions, and actions are taken for decision making). Furthermore, Super [31] proposed tasks of the developmental stage, which must be performed throughout the life of an individual. Super [31] stated that the career development stage of college students corresponds to the exploration period, in which careers are explored, considering the students' abilities, interests, values, and employment opportunities. The career development tasks in this period include making decisions for entering graduate school or searching for a job through a specific exploration of careers. The exploration stage has sub-stages of crystallization, specification, and implementation. The crystallization stage is a period in which career preference becomes apparent, as information about an individual and occupations is accumulated. The specification stage is a period in which a career preference becomes specific among several career preferences. Finally, the implementation stage is a period in which efforts are made towards the selected specific career.

Lee and Choi [32] divided the career development tasks required for university students into occupational awareness, career exploration, career design, career implementation, and career self-management. Occupational awareness refers to the overall understanding of university life adaptation and major, recognizing personal values, goals, and directions based on positive self-concept formation, positive attitude towards the work, and the significance of the occupation in the individual's life. Career exploration consists of a person's understanding of self-characteristics, in terms of career, self-understanding, various social and environmental characteristics, and career information exploration. Career design includes the establishment of career goals and them reflecting one's own characteristics and reality, and consists of planning, including self-development based on the career goal. Career implementation refers to cultivating vocational competence and preparing for transition into the labor market. Career self-management refers to meta-cognitive activities from a career perspective.

As a result of comprehensively analyzing previous studies on career development theories [30-32], it is concluded that the career development stage of university students is a period in which careers are explored, selected, and decided, and specific plans are established and implemented. However, career development theories have been criticized for not reflecting various factors of environmental changes sufficiently, because they only focused on the internal issues of individuals. This perspective of career development of university students is focused on identifying each person's interests, aptitudes, and abilities, and deciding on a career that is suitable for each person, but the personal characteristics and situations can change depending on personal circumstances in the rapidly changing and unpredictable occupational environment of the future. Therefore, this study examines adaptive factors that are required by Korean undergraduate students to perform career development tasks, considering the future occupational environment, and the cultural and social environments of South Korea. 


\section{Overview of the Studies}

The main research procedures for developing and validating the career adaptability scale for undergraduates are shown in Figure 1. The analysis method for designing and validating the career adaptability scale for undergraduates is described below. For the design of the scale, career adaptability and sub-factors were conceptualized through previous studies on career adaptability, and items were developed for each factor in study 1. In study 2, a Rasch model was used to analyze the fit of the preliminary test items, and an exploratory factor analysis (EFA) was conducted to examine the factor structures. In study 3, the Rasch model, a confirmatory factor analysis (CFA), and Cronbach's alpha were conducted to verify the validity and reliability of this test.

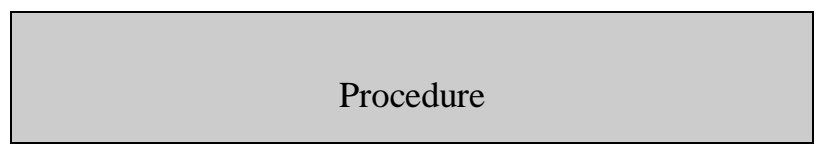

\begin{tabular}{|c|c|}
\hline \multirow[b]{3}{*}{ Study 1} & Establishment of the scale development plan \\
\hline & Л \\
\hline & $\begin{array}{c}\text { Conceptualization of career adaptability and } \\
\text { extraction of sub-factors }\end{array}$ \\
\hline
\end{tabular}

$\sqrt{3}$

\begin{tabular}{|c|c|}
\hline \multirow{4}{*}{ Study 2} & $\begin{array}{c}\text { Development of preliminary scale, } \\
\text { Investigation of the preliminary scale }(\mathrm{n}=141)\end{array}$ \\
\cline { 2 - 3 } & $\begin{array}{r}\text { Development of the main scale, } \\
\text { Investigation of the main scale }(\mathrm{n}=726)\end{array}$ \\
\hline
\end{tabular}

ת

\begin{tabular}{|l|c|}
\hline Study 3 & $\begin{array}{c}\text { Verification of the validity and reliability } \\
\text { of the main scale }\end{array}$ \\
\hline
\end{tabular}

\section{Analysis Method}

Validation of the definition of career adaptability for undergraduates and its sub-factors, through interviews and open-ended surveys with expert groups $(\mathrm{n}=15)$

EFA, Item fit analysis with Rasch model, Validation of preliminary items through expert groups

Final selection of items through item fit analysis, Content validation results with expert groups $(n=15)$

CFA, Item fit analysis with Rasch model

Validation of the item response categories curve and the scale

Verification of reliability

Figure 1. Research procedure and method.

3.1. Study 1: Conceptualizing Career Adaptability, Configuring Sub-Factors, and Development of Preliminary Scale

3.1.1. Method

Participants

Open surveys and interviews were conducted with 15 career education experts to derive the concept of career adaptability and extract sub-factors. The career education experts consisted of those who had a Ph.D. degree in Education or Business Administration and were responsible for career education in universities or had research experience related to careers. 


\section{Procedure and Instrument}

This study used existing concepts of career adaptability developed in South Korea and other countries as the basis. However, tasks that were considered important in the career development of undergraduate students were explored and used as the conceptual basis of career adaptability of undergraduate students, to further derive the concept of career adaptability of South Korean undergraduate students. First, 15 career education experts were asked to conduct a total of two surveys and advise to establish the concept of career adaptability and extract sub-factors. The questionnaire was created by the research team after reviewing previous studies conducted in South Korea and other countries and gathering the opinions of career education and counseling experts. The first open-ended questionnaire consisted of the following five items: "What is adaptability?", "What is career adaptability from the perspective of CCT?", "What is the career adaptability required in the future society?", "What are the career development tasks of undergraduate students in South Korea?", and "What are the important personal characteristics required to perform career development tasks of undergraduate students?"

The second questionnaire was composed based on the results of the first open-ended survey and the comprehensive analysis results of previous studies on development of the career adaptability scale. This questionnaire focused on the conceptualization of career adaptability of undergraduates and the validity of 11 sub-factors (self-understanding to establish identity, searching for a work environment, positive career beliefs, coping with career-choice crisis, career preparation behavior, adjusting career goals, coping with environmental stress, socially responsible behavior, utilizing social resources, coping with an uncertain future, and openness to career information) across three domains (knowledge and recognition of the self and work environment, self-directed coping related to career behavior, and environmental interaction for career decisions and adaptation). The results of examining the validity of the concept and sub-factors of career adaptability among panel members showed that the concept of career adaptability $(\mathrm{M}=4.5, \mathrm{SD}=0.89)$ and subfactors $(\mathrm{M}=4.00 \sim 4.88, \mathrm{SD}=0.63 \sim 1.00)$ had high content validity. In addition, as a result of examining the degree of consensus $(\geq 0.75)$ and convergence $(\leq 0.50)$ to calculate the degree of consensus among the panel members, it was found that the degree of consensus was 0.75 to 1.00 and the degree of convergence was 0.50 to 0.88 , which showed the degree of convergence was somewhat larger than 0.5 ; however, it was judged that the opinions of the panel members were agreed by reflecting the results of the content validity of the panel members (see Table 2).

Table 2. Conceptual definition of sub-factors of career adaptability and content validity analysis for the preliminary scale.

\begin{tabular}{|c|c|c|c|c|c|}
\hline Sub-Factor & Definition & $\mathbf{M}$ & SD & Consensus & Convergence \\
\hline \multicolumn{6}{|c|}{ Knowledge and recognition of self and work environment } \\
\hline $\begin{array}{l}\text { Understanding self to } \\
\text { establish identity }\end{array}$ & $\begin{array}{l}\text { Ability to reflect on one's personality, interest, } \\
\text { aptitude, and values, in connection with one's } \\
\text { job, to clarify vocational self-concepts }\end{array}$ & 4.38 & 0.52 & 0.75 & 0.50 \\
\hline $\begin{array}{l}\text { Searching for a work } \\
\text { environment }\end{array}$ & $\begin{array}{l}\text { Tendency to explore jobs and the future world } \\
\text { with constant curiosity to collect information } \\
\text { about future vocation }\end{array}$ & 4.29 & 0.49 & 0.75 & 0.50 \\
\hline Positive career beliefs & $\begin{array}{l}\text { Belief that current efforts will result in positive } \\
\text { outcomes related to career and jobs }\end{array}$ & 4.14 & 0.69 & 0.75 & 0.50 \\
\hline
\end{tabular}


Table 2. Cont.

\begin{tabular}{|c|c|c|c|c|c|}
\hline Sub-Factor & Definition & $\mathbf{M}$ & SD & Consensus & Convergence \\
\hline \multicolumn{6}{|c|}{ Self-directed coping related to career behavior } \\
\hline $\begin{array}{c}\text { Coping with career-choice } \\
\text { crisis }\end{array}$ & $\begin{array}{l}\text { Ability to compare, analyze, integrate, and judge } \\
\text { the alternatives necessary to solve crises arising } \\
\text { in career choices }\end{array}$ & 4.71 & 0.49 & 0.67 & 0.50 \\
\hline Career preparation behavior & $\begin{array}{l}\text { Engaging in new education, training, and } \\
\text { various activities to anticipate changes in job } \\
\text { requirements and prepare for them }\end{array}$ & 4.38 & 0.92 & 0.65 & 0.88 \\
\hline Adjusting career goals & $\begin{array}{l}\text { Ability to adjust or reset goals when it is difficult } \\
\text { to reach the initially planned goals; adjustments } \\
\text { necessary while pursuing career goals }\end{array}$ & 4.63 & 0.52 & 0.80 & 0.50 \\
\hline \multicolumn{6}{|c|}{ Environmental interaction for career decisions and adaptation } \\
\hline $\begin{array}{c}\text { Coping with environmental } \\
\text { stress }\end{array}$ & $\begin{array}{l}\text { Seeking constructive measures with optimism to } \\
\text { overcome stressful situations experienced } \\
\text { during career exploration and pioneering }\end{array}$ & 4.57 & 0.53 & 0.80 & 0.50 \\
\hline $\begin{array}{l}\text { Socially responsible } \\
\text { behavior }\end{array}$ & $\begin{array}{l}\text { Taking responsibility for one's own work when } \\
\text { working with others, respecting other's views } \\
\text { and opinions, and cooperating to reconcile any } \\
\text { differences }\end{array}$ & 4.88 & 0.35 & 1.00 & 0.00 \\
\hline Utilizing social resources & $\begin{array}{l}\text { Ability to utilize social networks (to receive } \\
\text { emotional, instrumental, and practical support } \\
\text { through various support systems) to achieve } \\
\text { career goals or solve problems }\end{array}$ & 4.71 & 0.76 & 1.00 & 0.00 \\
\hline $\begin{array}{c}\text { Coping with an uncertain } \\
\text { future }^{\mathrm{a}}\end{array}$ & $\begin{array}{l}\text { Ability to swiftly choose and execute effective } \\
\text { plans, goals, and actions to cope with } \\
\text { unpredictable situations }\end{array}$ & 4.38 & 0.92 & 0.67 & 0.50 \\
\hline $\begin{array}{l}\text { Openness to career } \\
\text { information }^{\mathrm{a}}\end{array}$ & $\begin{array}{l}\text { Tendency to feel less uncomfortable and actively } \\
\text { explore unfamiliar or complex information, } \\
\text { encountered during career decisions, with an } \\
\text { open attitude }\end{array}$ & 4.00 & 0.76 & 0.63 & 0.75 \\
\hline
\end{tabular}

${ }^{a}$ Coping with an uncertain future and openness to career information were deleted from the main scale based on item analysis and content validity test.

Second, based on the definitions of each sub-factor, the existing domestic and international career adaptability scales $[10-12,14,27]$ and career adaptability-related scales [24] have been revised and complemented to develop preliminary items for the career adaptability scale for undergraduates. To examine the adequacy of the preliminary items developed, 15 career training experts were asked to participate in the content validity verification process and seven undergraduates were asked to provide feedback on the comprehensibility of the items. The intention of the process was to develop a highly practical scale in the actual education field by considering the opinions of educators in charge of career education and undergraduate students in universities.

\subsubsection{Results}

First, the open-ended survey categorized and analyzed the frequency of the responses to the definition of adaptability, the future career world, career adaptability related to career developmental tasks of undergraduates, and the characteristics of the career adaptability of undergraduates. These were divided into the following three areas: knowledge and recognition of the self and work environment, self-directed coping related to career behavior, and environmental interaction for career decisions and adaptation. This study conceptualizes career adaptability as "the adaptability and self-controlling strategies to properly cope with career developmental tasks and future career challenges necessary for a successful career transition". The adaptive characteristics of individuals are categorized 
into the following 11 factors: self-understanding to establish identity, searching for a work environment, positive career beliefs, coping with career-choice crisis, career preparation behavior, adjusting career goals, coping with environmental stress, socially responsible behavior, utilizing social resources, coping with an uncertain future, and openness to career information. Second, after validation of the content by the expert group, the following sub-factors were removed based on the opinion that they overlapped with other sub-factors: coping with an uncertain future and openness to career information. The definitions of the final career adaptability sub-factors and the results of the content validity analysis are presented in Table 2. As shown in the table, the expert panel agreed with a consensus of more than 0.75 and a convergence of less than 0.50 [33]. The preliminary questionnaire was developed with 63 items and Likert scale $(1=$ strongly disagree $4=$ strongly agree $)$ items, measuring a total of nine sub-factors, which have seven items, respectively. The items of the preliminary test were developed by five career education and counseling experts based on prior research. In addition, as a result of conducting a questionnaire to verify the content validity, with 15 career education experts for content validity analysis for each item, the average content validity index (CVI) of 63 items was $4.68 \sim 4.80(\mathrm{SD}=0.45 \sim 0.89)$, indicating that the content validity was high. The consensus and convergence analyses of the items found that the degree of consensus was 0.80 to 1.00 and the degree of convergence was 0.00 to 0.50 , indicating that there was a consensus on the opinions of the experts.

\subsection{Study 2: Item Fit Analysis Using Rasch Model and Exploratory Factor Analysis \\ 3.2.1. Method \\ Participants}

A total of 141 students from a South Korean private university, which the author is affiliated with, responded to the preliminary career adaptability scale. Of these participants, 63 were male $(44.68 \%)$ and 78 were female $(55.32 \%)$. Among them, 59 were freshmen $(41.84 \%), 37$ sophomore (26.24\%), 24 junior (17.02\%), and 21 senior $(14.89 \%)$. Participating students had diverse majors, which were as follows: $15(10.64 \%)$ were from the College of Social Sciences, $21(14.89 \%)$ from the College of Health Sciences, $33(23.4 \%)$ from the College of Biotechnology, 35 (24.82\%) from the College of Convergence Technology, 23 (16.31\%) from the College of Natural Sciences, and 14 (9.93\%) from the College of Arts.

Procedure and Analyses

The following procedures were performed to verify the validity of the preliminary test. The data were analyzed based on the Rasch model using Winsteps version 4.7.1 statistical program [34]. A residual principal component analysis was performed to confirm whether the unidimensionality assumption held. Item parameters, infit MnSq and outfit MnSq index, the adequacy statistics, were calculated. In order to verify the item validity based on the Rasch model, an item fit analysis was performed by applying the Rasch model. Item validity can be interpreted as how well students' responses to the items agree with the expected ones. Since outfit MnSq is calculated including all extreme reactions, it can be affected by the extreme value, whereas infit MnSq calculates the index by reducing the influence of the extreme reaction, since infit $\mathrm{MnSq}$ is usually used to determine the degree of fit. When the fit index MnSq value is 1.0 or higher, it means that the model often deviates from the expected response. The criteria for determining nonconforming items may vary depending on the sample size or situation, but Lunz, Stahl, and Wright [35] suggest 1.5 as the criteria for determining nonconforming items.

Second, to explore factor structures, the SPSS 23.0 program was used to conduct the EFA by oblique rotation considering the correlation between factors, and the number of factors was determined based on the eigenvalues, the scree plot, and goodness-of-fit indices. 


\subsubsection{Results}

The Rasch model was used to analyze the fit of the preliminary test items. In order to confirm the suitability of the item of the preliminary test, expected a posteriori reliability/plausible values (EAP/PV) reliability was used as a value to check whether the participant's ability was appropriate, and the item reliability was used as a value to check whether the difficulty of the items could distinguish the students' abilities. An item reliability of 0.9 or more, and EAP/PV reliability of 0.8 or more can be said to be very suitable [36]. In this study, the item reliability of the study was 0.91 , which was suitable for confirming the quality level of the test tool by the participants. In addition, the EAP/PV reliability was 0.88 , confirming that the items are an appropriate tool to classify the level of career adaptability of the participants. The results of evaluating unidimensionality, including a total of 63 items, are as follows. A principal components analysis of the residuals showed that the Rasch dimension explained $51.1 \%$ of the variance in the data [37]. The largest secondary dimension explained $7.8 \%$, with an eigenvalue of 1.8 (eigenvalue $<2$ ) [38], which implies that unidimensionality was satisfied.

When the MnSq value of the infit is greater than 1.5, or when the Zstd value is greater than 2, the adequacy of the data is doubted. In addition, the point-measure correlation (PT-MEA Corr.) is the correlation between the response score of each item and the total participants measurement. Generally, an item is considered for review when the value is less than 0.3 [39]. The analysis of the items fit in the preliminary scale showed that a total of seven items were inadequate (see Table 3). Forty-five items were selected to develop the main test for consideration of the results of the item fit analysis and the content validity of the panelists.

Table 3. Item fit analysis using Rasch model in the preliminary scale: unfit items.

\begin{tabular}{cccccccc}
\hline \multirow{2}{*}{ Item } & \multirow{2}{*}{ Value } & \multirow{2}{*}{ Error } & \multicolumn{2}{c}{ Infit } & \multicolumn{2}{c}{ Outfit } & PT-MEA \\
\cline { 4 - 7 } & & & MnSq & Zstd. & MnSq & Zstd. & \\
\hline NT_06 & 4.64 & 0.13 & 1.22 & 2.63 & 1.57 & 2.65 & 0.58 \\
\hline GC_06 & -0.53 & 0.13 & 1.24 & 2.45 & 3.93 & 7.73 & 0.04 \\
\hline SF_01 & -1.71 & 0.21 & 1.01 & 0.12 & 2.38 & 3.28 & 0.13 \\
\hline PS_06 & -0.31 & 0.12 & 1.18 & 2.13 & 2.3 & 4.83 & 0.15 \\
\hline OP_03 & -1.05 & 0.16 & 1.04 & 0.32 & 1.65 & 2.19 & 0.19 \\
\hline OP_02 & -0.33 & 0.12 & 0.99 & -0.04 & 1.55 & 2.37 & 0.28 \\
\hline CL_06 & -2.06 & 0.24 & 1.02 & 0.14 & 1.51 & 1.4 & 0.12 \\
\hline
\end{tabular}

As a result of the test of normality for the participants before the EFA, the results of the Kolmogorov-Smirnov normality test did not satisfy a normal distribution in a total of seven items, but the values of skewness and kurtosis were between -2 and 2 [40]. Thus, CFA was performed, assuming a normal distribution. In addition, to determine whether the EFA is possible for a sample, the KMO measure, Bartleet's sphericity, and correlation matrix between items were examined. The KMO measure value of the career adaptability scale was 0.938 and the Bartleet's sphericity test value was 21,023.63 ( $\mathrm{df}=2415, p<0.000)$, confirming that there are common factors that can be analyzed. As a result of the analysis of the correlation matrix table, it was also confirmed that the correlation between the items was not greater than 0.8 , so no multicollinearity problem was found [41].

The results of the EFA are presented in Table 4 . A total of nine factor structures were found to be the most significant based on repeated analyses to choose the appropriate number of factors, by identifying factors with eigenvalues greater than 1.0 and designating the number of factors from eight to eleven based on the scree plot. When the factor loading was at least 0.30 or above, it was considered a good item, and if an item had a factor loading of 0.30 or above for both factors, and the difference in the factor loading was less 
than 0.10, it was judged to be cross-loaded [42]. Finally, a total of 45 items and 9 factor structures were developed through the results of the EFA and content validity test. In other words, the final questionnaire, consisting of 45 items, comprised the following nine factors: self-understanding to establish identity, search for work environment, positive career beliefs, coping with career-choice crisis, career preparation behavior, ability to coordinate career goals, ability to cope with environmental stress, social responsibility, and ability to utilize social resources. Some items (items 23, 28, and 45) had higher factor loadings for factors other than those that were previously set, but the statistical figures and experts content validity were also verified through the content validity process. The nine factors, accounting for approximately $46.32 \%$ of the total variance, met the requirement of at least $40 \%$ of the descriptive variables to define the factor structure [43].

Table 4. Exploratory factor analysis result: component loading and communality estimates.

\begin{tabular}{|c|c|c|c|c|c|c|c|c|c|c|c|}
\hline Factor & $\begin{array}{l}\text { Item } \\
\text { No. }\end{array}$ & 1 & 2 & 3 & 4 & 5 & 6 & 7 & 8 & 9 & $h^{2}$ \\
\hline \multirow{5}{*}{$\begin{array}{c}\text { Career } \\
\text { preparation } \\
\text { behavior }\end{array}$} & Item04 & 0.717 & 0.160 & 0.123 & 0.161 & 0.120 & 0.148 & -0.018 & 0.036 & 0.076 & 0.624 \\
\hline & Item03 & 0.681 & 0.126 & 0.157 & 0.066 & 0.121 & 0.186 & 0.003 & 0.055 & -0.032 & 0.562 \\
\hline & Item01 & 0.658 & 0.145 & 0.124 & 0.091 & 0.146 & 0.119 & 0.051 & 0.046 & 0.206 & 0.560 \\
\hline & Item02 & 0.619 & 0.146 & 0.053 & 0.260 & 0.134 & 0.130 & 0.148 & -0.040 & 0.146 & 0.555 \\
\hline & Item05 & 0.453 & 0.174 & 0.183 & 0.217 & 0.033 & -0.040 & -0.066 & 0.009 & 0.357 & 0.450 \\
\hline \multirow{5}{*}{$\begin{array}{l}\text { Positive career } \\
\text { beliefs }\end{array}$} & Item06 & 0.174 & 0.729 & 0.082 & 0.126 & 0.146 & 0.122 & 0.068 & 0.124 & 0.066 & 0.645 \\
\hline & Item 10 & 0.223 & 0.704 & 0.097 & 0.054 & 0.070 & 0.043 & 0.075 & 0.041 & -0.038 & 0.573 \\
\hline & Item09 & 0.131 & 0.686 & 0.232 & 0.125 & 0.109 & 0.142 & 0.038 & 0.020 & 0.016 & 0.592 \\
\hline & Item07 & 0.217 & 0.572 & 0.280 & 0.161 & 0.110 & 0.115 & 0.104 & 0.019 & 0.146 & 0.537 \\
\hline & Item08 & 0.180 & 0.521 & 0.338 & 0.075 & 0.217 & 0.037 & -0.016 & -0.070 & 0.030 & 0.478 \\
\hline \multirow{5}{*}{$\begin{array}{l}\text { Coping with } \\
\text { career-choice } \\
\text { crisis }\end{array}$} & Item12 & 0.145 & 0.201 & 0.665 & -0.035 & 0.121 & -0.034 & 0.067 & 0.068 & 0.039 & 0.531 \\
\hline & Item13 & 0.142 & 0.125 & 0.653 & -0.027 & -0.025 & 0.026 & 0.163 & 0.090 & 0.037 & 0.500 \\
\hline & Item11 & 0.098 & 0.071 & 0.572 & 0.130 & 0.193 & 0.127 & -0.126 & 0.045 & -0.019 & 0.431 \\
\hline & Item15 & 0.205 & 0.134 & 0.565 & 0.009 & 0.111 & 0.114 & 0.076 & 0.003 & -0.043 & 0.412 \\
\hline & Item14 & 0.100 & 0.237 & 0.517 & 0.178 & 0.057 & 0.072 & 0.015 & 0.037 & 0.099 & 0.385 \\
\hline \multirow{5}{*}{$\begin{array}{l}\text { Utilizing social } \\
\text { resources }\end{array}$} & Item20 & 0.118 & 0.093 & 0.109 & 0.688 & 0.057 & 0.090 & 0.061 & 0.103 & -0.003 & 0.533 \\
\hline & Item16 & 0.222 & 0.026 & 0.117 & 0.639 & 0.112 & 0.039 & 0.066 & 0.156 & 0.002 & 0.514 \\
\hline & Item19 & 0.196 & 0.258 & 0.176 & 0.521 & 0.090 & -0.028 & -0.129 & -0.239 & -0.060 & 0.494 \\
\hline & Item17 & 0.117 & 0.288 & 0.292 & 0.473 & 0.147 & 0.020 & -0.058 & -0.261 & -0.068 & 0.504 \\
\hline & Item18 & 0.058 & 0.110 & -0.144 & 0.419 & -0.009 & 0.124 & 0.082 & -0.005 & 0.219 & 0.282 \\
\hline \multirow{5}{*}{$\begin{array}{l}\text { Understanding } \\
\text { self to establish } \\
\text { identity }\end{array}$} & Item 25 & 0.332 & 0.189 & 0.187 & 0.075 & 0.580 & -0.051 & 0.013 & 0.044 & 0.038 & 0.484 \\
\hline & Item 24 & 0.268 & 0.224 & 0.211 & 0.049 & 0.547 & 0.014 & 0.015 & 0.110 & 0.057 & 0.529 \\
\hline & Item22 & 0.319 & 0.126 & 0.191 & 0.083 & 0.449 & 0.001 & 0.029 & 0.205 & -0.063 & 0.409 \\
\hline & Item21 & 0.319 & 0.132 & 0.119 & 0.095 & 0.204 & 0.082 & 0.085 & 0.491 & -0.008 & 0.439 \\
\hline & Item23 & 0.223 & 0.230 & 0.172 & 0.077 & 0.176 & 0.137 & -0.020 & 0.340 & 0.039 & 0.305 \\
\hline
\end{tabular}


Table 4. Cont.

\begin{tabular}{|c|c|c|c|c|c|c|c|c|c|c|c|}
\hline Factor & $\begin{array}{l}\text { Item } \\
\text { No. }\end{array}$ & 1 & 2 & 3 & 4 & 5 & 6 & 7 & 8 & 9 & $h^{2}$ \\
\hline \multirow{5}{*}{$\begin{array}{l}\text { Coping with } \\
\text { environmental } \\
\text { stress }\end{array}$} & Item30 & 0.146 & 0.097 & 0.049 & 0.058 & -0.015 & 0.602 & 0.027 & 0.052 & -0.038 & 0.404 \\
\hline & Item 29 & 0.167 & 0.154 & 0.082 & 0.138 & 0.058 & 0.515 & 0.209 & 0.013 & 0.188 & 0.425 \\
\hline & Item 26 & 0.104 & 0.389 & 0.232 & 0.131 & 0.091 & 0.498 & 0.018 & 0.043 & 0.009 & 0.491 \\
\hline & Item 27 & 0.184 & 0.076 & -0.065 & 0.209 & 0.003 & 0.421 & 0.152 & 0.105 & 0.269 & 0.371 \\
\hline & Item 28 & 0.363 & 0.109 & 0.129 & 0.109 & 0.273 & 0.150 & 0.119 & 0.125 & 0.139 & 0.318 \\
\hline \multirow{5}{*}{$\begin{array}{l}\text { Socially } \\
\text { responsible } \\
\text { behavior }\end{array}$} & Item32 & 0.126 & 0.162 & 0.198 & 0.190 & 0.126 & 0.296 & 0.475 & 0.090 & 0.060 & 0.458 \\
\hline & Item35 & 0.140 & 0.242 & 0.196 & 0.147 & 0.171 & 0.221 & 0.426 & 0.067 & 0.166 & 0.429 \\
\hline & Item34 & 0.158 & 0.343 & 0.155 & 0.071 & 0.023 & 0.389 & 0.419 & 0.084 & 0.047 & 0.508 \\
\hline & Item33 & 0.330 & 0.270 & 0.185 & 0.156 & 0.136 & 0.169 & 0.369 & 0.067 & 0.058 & 0.431 \\
\hline & Item31 & 0.188 & 0.284 & 0.224 & 0.066 & 0.050 & 0.212 & 0.523 & 0.072 & 0.062 & 0.501 \\
\hline \multirow{5}{*}{$\begin{array}{c}\text { Searching for a } \\
\text { work } \\
\text { environment }\end{array}$} & Item 40 & 0.074 & 0.104 & 0.074 & 0.035 & 0.203 & 0.067 & 0.289 & 0.298 & 0.124 & 0.257 \\
\hline & Item39 & 0.138 & 0.147 & 0.148 & 0.106 & 0.189 & 0.036 & 0.112 & 0.686 & -0.115 & 0.607 \\
\hline & Item36 & 0.122 & 0.159 & 0.163 & 0.079 & 0.143 & 0.031 & 0.152 & 0.604 & -0.059 & 0.485 \\
\hline & Item37 & 0.060 & 0.290 & 0.229 & 0.177 & 0.267 & 0.166 & -0.011 & 0.354 & 0.192 & 0.432 \\
\hline & Item 38 & 0.002 & 0.138 & -0.004 & 0.152 & 0.346 & 0.158 & 0.270 & 0.271 & -0.056 & 0.337 \\
\hline \multirow{5}{*}{$\begin{array}{c}\text { Adjusting career } \\
\text { goals }\end{array}$} & Item 45 & 0.396 & 0.241 & 0.268 & 0.168 & 0.088 & 0.100 & 0.113 & -0.033 & 0.060 & 0.350 \\
\hline & Item 44 & 0.200 & 0.266 & -0.082 & 0.198 & 0.218 & 0.132 & 0.246 & -0.028 & 0.402 & 0.445 \\
\hline & Item 43 & 0.142 & 0.148 & 0.052 & 0.174 & 0.323 & 0.117 & 0.300 & -0.020 & 0.371 & 0.421 \\
\hline & Item41 & 0.063 & 0.278 & 0.164 & 0.007 & 0.317 & 0.259 & 0.039 & -0.097 & 0.355 & 0.413 \\
\hline & Item 42 & 0.253 & 0.206 & 0.368 & 0.203 & 0.101 & 0.166 & 0.109 & -0.014 & 0.312 & 0.430 \\
\hline \multicolumn{2}{|c|}{ Eigenvalue } & 4.586 & 4.194 & 3.513 & 2.384 & 1.902 & 1.728 & 1.077 & 0.735 & 0.724 & \\
\hline \multicolumn{2}{|c|}{$\%$ of Variance } & 10.192 & 9.321 & 7.806 & 5.298 & 4.226 & 3.840 & 2.393 & 1.634 & 1.610 & \\
\hline \multicolumn{2}{|c|}{$\%$ of cumulative variance } & 10.192 & 19.512 & 27.318 & 32.617 & 36.843 & 40.683 & 43.076 & 44.710 & 46.320 & \\
\hline
\end{tabular}

3.3. Study 3: Verification of the Appropriateness of the Response Scale Using the Rasch Model, Confirmatory Factor Analysis, and Reliability of Main Scale

\subsubsection{Method}

Participants

A total of 726 college students from seven universities, including 5 private universities and 2 public universities in South Korea, responded to the main career adaptability scale for purposive sampling. Of these participants, 320 were male (44.1\%) and 406 were female $(55.98 \%)$. Among them, 218 were freshmen $(30.03 \%), 179$ sophomore $(24.66 \%), 172$ junior $(23.63 \%)$, and 157 senior $(21.63 \%)$. Participating students had diverse majors, which were as follows: 93 (12.81\%) were from the College of Social Sciences, 75 (10.33\%) from the College of Health Sciences, 154 (21.21\%) from the College of Biotechnology, 175 (24.10\%) from the College of Convergence Technology, 124 (17.08\%) from the College of Natural Sciences, and $105(14.46 \%)$ from the College of Arts.

Procedure and Analyses

The research procedures for verifying the validity and reliability of the test tool in this study were as follows. First, the Rasch model was used to calculate the fit of the items to check inappropriate items in this test. This procedure is the same as that presented in study 2. The final test items were determined based on the results of item fit analysis of the items and the validation results of the experts. Second, CFA was conducted using AMOS 22.0 to 
verify the validity of the factor structures of the scale. The maximum likelihood method was used as the estimation method of the model, and the missing value estimation was performed using the full information maximum likelihood (FLML) method to calculate standardized regression weights, error, concept reliability, and variance extraction index. Third, the distributions of the survey participants and the items were calculated based on the Rasch measurements to compare the distributions simultaneously according to the career adaptability of undergraduate students and the difficulty level of the items. Fourth, Cronbach's alpha and stratified alpha were calculated to verify the reliability of the developed scale.

\subsubsection{Results}

\section{Verification of Item Validity Using the Rasch Model}

The item reliability of the main test was 0.99 , confirming that the study participant was suitable for confirming the quality level of the main test. In addition, the EAP/PV reliability was 0.84 , confirming that it is a suitable test to classify the level of career adaptability of the participants in the items of the test [36]. The results of unidimensionality, including all 44 items, are as follows. Career adaptability showed that the Rasch dimension explained $46 \%$ of the observed variance in the data, which is extremely close to the Rasch model prediction of $46.2 \%$, indicating that the computation of the Rasch difficulty measures was successful [37]. The loading patterns of the items on the first hypothesized contrast in the linearized residuals were explored. The items did not form distinguishable patterns or clusters, they scattered in different regions of the map; this supports unidimensionality [37]. The largest secondary dimension explained 6.5\%, with an eigenvalue of 1.7 (eigenvalue <2) [38], which supports the presumption that the data set is unidimensional.

The Rasch model was applied for the verification of item validity, to check for inappropriate items and to measure career adaptability. According to the analysis of the main test developed in this study (see Table 5), one out of 45 items had a Zstd value of 2.63, exceeding 2 for internal consistency; an MnSq value of 1.57, exceeding 1.5 for external consistency; and a Zstd value of 2.65, exceeding 2, which meant that a review was required. Item NT03, "I ask for others' support in changing my career plans (professors, parents, older friends, etc.)", refers to "the ability to utilize social resources" in "the environmental interaction for career decision and adaption" area. However, there was a risk of it overlapping with "adjusting career goals". Consequently, item NT03 was excluded from the analysis because of the ambiguity of the behavioral characteristics and the risk of overlapping with one or more factors.

Table 5. Adequacy analysis of the items in the main scale.

\begin{tabular}{cccccccc}
\hline \multirow{2}{*}{ Item } & \multirow{2}{*}{ Value } & \multirow{2}{*}{ Error } & \multicolumn{2}{c}{ Infit } & \multicolumn{2}{c}{ Outrit } & \multirow{2}{*}{ PT-MEA } \\
\cline { 5 - 8 } & & & MnSq & Zstd. & MnSq & Zstd. & Corr. \\
\hline NT 03 & 4.64 & 0.13 & 1.22 & 2.63 & 1.57 & 2.65 & 0.58 \\
\hline
\end{tabular}

Differential item functioning (DIF) was evaluated to check the generalization validity. Assuming that the career adaptability test can be used for gender comparison studies, the DIF analysis for gender was explored. In the analysis of the Rasch model, it can be said that a discriminatory item function appears when the difference in DIF value is 0.64 or more [36]. When analyzed by gender, two items (DIF contrasts of item $1=0.75$ and item $35=1.08$, respectively) were found to be greater than 0.64 among the absolute values of the DIF difference values of the total significant level. To item 1 (I seriously consider my career and related concerns), women responded more positively, and to item 35 (I solve problems with my peers), men responded more positively. 


\section{Verification of Construct Validity and Reliability}

A result of the normality test of the participants to carry out the CFA showed that the values of skewness and kurtosis were between -2 and 2 [40], and thus a normal distribution was assumed. In addition, to determine whether EFA is possible for a sample, the KMO measure, Bartleet's sphericity, and correlation matrix between items were examined. It was confirmed that there are common factors that can be analyzed based on the result that the KMO measure value of the career adaptability scale was 0.926 and the Bartleet's sphericity test value was $1113.31(\mathrm{df}=990, p<0.000)$. As a result of the analysis of the correlation matrix table, it was also confirmed that the correlation between the items was not greater than 0.8 , so no multicollinearity problem was found [41].

CFA was conducted using the AMOS 22.0 program to validate the structure of three domains and nine factors for 44 items of the career adaptability scale. The research model was assumed based on theoretical and empirical studies, and a hierarchical secondary factor model was used for measurements. As a result of examining the fit index to determine the model fit of the structural equation model, the absolute fit index RMR, GFI, and RMSEA values, and the incremental fit index IFI, TLI, and CFI values were RMR $=0.057, \mathrm{GFI}=0.825$, RMSEA $=0.057$, SRMR $=0.063, \mathrm{IFI}=0.927$, TLI $=0.917$, and CFI $=0.923$ in Table 6. Of the absolute fit indices, only GFI was slightly below the standard 0.9, RMR, RMSEA, and SRMR met the 0.05 to 0.08 or lower standards, and IFI, TLI, and CFI all met the 0.9 or higher standard. Therefore, it was judged that the collected data were suitable to explain the research model (see Table 6).

Table 6. Hierarchical factor model.

\begin{tabular}{|c|c|c|c|c|c|c|c|c|c|}
\hline Model & $x^{2}$ & $x^{2} / \mathrm{df}$ & RMR & GFI & RMSEA & SRMR & IFI & TLI & CFI \\
\hline Hierarchical Factor Model & $588.147^{* * *}$ & 1.598 & 0.057 & 0.825 & 0.057 & 0.063 & 0.927 & 0.917 & 0.923 \\
\hline Criterion & & & $0.05 \sim 0.08$ & $\geq 0.9$ & $0.05 \sim 0.08$ & $0.05 \sim 0.08$ & $\geq 0.9$ & $\geq 0.9$ & $\geq 0.9$ \\
\hline
\end{tabular}

This indicates that the hierarchical factor model fits well with the data collected. The standardized coefficient estimates for the model are shown in Table 7, with the factor loading, which indicates the relationship between each item and the related primary factors, ranging from 0.318 to 0.817 and $p<0.001$. The mean for each question was 1.86 3.50 $(\mathrm{SD}=0.492 \sim 0.791)$, skewness was $-0.544 \sim 0.716$, and kurtosis was $-1.541 \sim$, which was 1.81. In addition, the concept reliability showed that the values ranged from 0.944 to 0.984 , exceeding the standard value of 0.7 , while the variance extraction index ranged from 0.920 to 0.959 , meeting the requirement of greater than 0.5 and securing convergent validity [44]. 
Table 7. Validity, reliability and descriptive statistics of the final version of the scale.

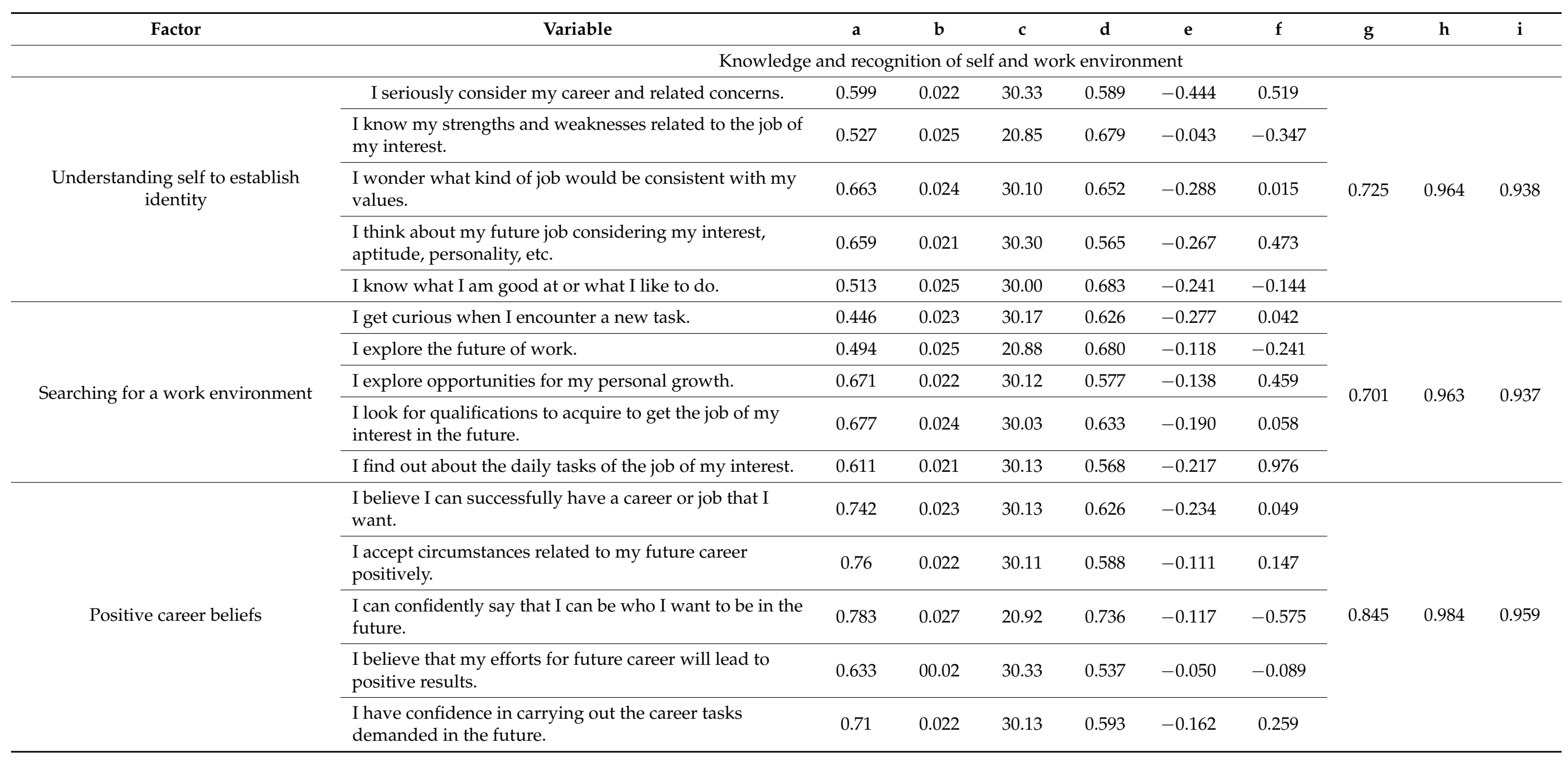


Table 7. Cont.

\begin{tabular}{|c|c|c|c|c|c|c|c|c|c|c|}
\hline Factor & Variable & a & b & c & d & e & $\mathbf{f}$ & g & $\mathbf{h}$ & $\mathbf{i}$ \\
\hline & \multicolumn{10}{|c|}{ Self-directed coping related to career behavior } \\
\hline \multirow{4}{*}{ Coping with career-choice crisis } & $\begin{array}{l}\text { I take the given circumstances as a challenge } \\
\text { (opportunity) rather than a problem. }\end{array}$ & 0.658 & 0.024 & 20.93 & 0.652 & -0.115 & -0.168 & \multirow{4}{*}{0.790} & \multirow{4}{*}{0.978} & \multirow{4}{*}{0.953} \\
\hline & $\begin{array}{l}\text { I quickly find a way to cope with unexpected difficulties } \\
\text { or crises. in the career choice process. }\end{array}$ & 0.621 & 0.022 & 30.01 & 0.597 & -0.202 & 0.498 & & & \\
\hline & I solve career problems head-on without avoiding them. & 0.663 & 0.022 & 20.97 & 0.597 & -0.150 & 0.317 & & & \\
\hline & I can overcome the potential obstacles in my career path. & 0.675 & 0.018 & 30.05 & 0.492 & -0.097 & 10.805 & & & \\
\hline \multirow{5}{*}{ Career preparation behavior } & $\begin{array}{l}\text { I make plans to engage in activities that help make my } \\
\text { resume look better. }\end{array}$ & 0.561 & 0.026 & 20.86 & 0.683 & -0.032 & -0.411 & \multirow{5}{*}{0.832} & \multirow{5}{*}{0.983} & \multirow{5}{*}{0.957} \\
\hline & I constantly collect the latest information for my future. & 0.716 & 0.025 & 20.78 & 0.669 & -0.023 & -0.281 & & & \\
\hline & I pursue the education I need to achieve my career goals & 0.742 & 0.021 & 30.05 & 0.575 & -0.176 & 0.705 & & & \\
\hline & $\begin{array}{l}\text { I research career activities I need to do to achieve my } \\
\text { career goals. }\end{array}$ & 0.817 & 0.022 & 30.03 & 0.581 & -0.261 & 0.909 & & & \\
\hline & $\begin{array}{l}\text { I seek ways to acquire skills necessary for my job and the } \\
\text { field of my interest. }\end{array}$ & 0.727 & 0.021 & 30.06 & 0.560 & -0.077 & 0.543 & & & \\
\hline \multirow{5}{*}{ Adjusting career goals } & $\begin{array}{l}\text { I try to engage in new activities considering different } \\
\text { possibilities. }\end{array}$ & 0.632 & 0.023 & 30.02 & 0.608 & -0.120 & 0.104 & \multirow{5}{*}{0.746} & \multirow{5}{*}{0.970} & \multirow{5}{*}{0.945} \\
\hline & $\begin{array}{l}\text { The struggles I experience as I prepare for my career are } \\
\text { ultimately helpful to me. }\end{array}$ & 0.554 & 0.022 & 30.22 & 0.578 & -0.317 & 0.961 & & & \\
\hline & $\begin{array}{l}\text { I adjust my prior plans, goals, actions, and priorities } \\
\text { appropriately to reach my career goals. }\end{array}$ & 0.597 & 0.022 & 30.07 & 0.580 & -0.177 & 0.630 & & & \\
\hline & $\begin{array}{l}\text { I comfortably accept various information in the career } \\
\text { decision-making process. }\end{array}$ & 0.648 & 0.02 & 30.16 & 0.529 & -0.023 & 10.054 & & & \\
\hline & $\begin{array}{l}\text { I enjoy taking various perspectives while solving a career } \\
\text { problem. }\end{array}$ & 0.619 & 0.022 & 30.19 & 0.592 & -0.243 & 0.383 & & & \\
\hline
\end{tabular}


Table 7. Cont.

\begin{tabular}{|c|c|c|c|c|c|c|c|c|c|c|}
\hline Factor & Variable & $\mathbf{a}$ & $\mathbf{b}$ & c & d & e & $\mathbf{f}$ & g & $\mathbf{h}$ & i \\
\hline & Environment & interac & for car & decisic & and ad & tation & & & & \\
\hline \multirow{4}{*}{ Coping with environmental stress } & $\begin{array}{l}\text { I constantly think about my career, even when I need to } \\
\text { focus on studying. }\end{array}$ & 0.537 & 0.027 & 20.90 & 0.721 & -0.074 & -0.562 & \multirow{4}{*}{0.654} & \multirow{4}{*}{0.944} & \multirow{4}{*}{0.920} \\
\hline & I seek solutions to overcome career stress situations. & 0.415 & 0.028 & 20.19 & 0.737 & 0.479 & 0.231 & & & \\
\hline & $\begin{array}{l}\text { I remain calm even when I am stressed out about my } \\
\text { career. }\end{array}$ & 0.464 & 0.026 & 20.72 & 0.703 & -0.497 & 0.285 & & & \\
\hline & $\begin{array}{l}\text { I can overcome stressful situations I experience as I study } \\
\text { or prepare my career goals. }\end{array}$ & 0.628 & 0.021 & 20.96 & 0.558 & -0.504 & 10.811 & & & \\
\hline \multirow{5}{*}{ Socially responsible behavior } & I solve problems with my peers. & 0.606 & 0.022 & 30.23 & 0.581 & -0.248 & 0.450 & \multirow{5}{*}{0.775} & \multirow{5}{*}{0.977} & \multirow{5}{*}{0.954} \\
\hline & $\begin{array}{l}\text { I take responsibility for my job when working with } \\
\text { others for a common task. }\end{array}$ & 0.721 & 0.019 & 30.50 & 0.517 & -0.173 & -10.541 & & & \\
\hline & $\begin{array}{l}\text { I revise my opinion by listening to and considering other } \\
\text { people's perspectives and opinions. }\end{array}$ & 0.624 & 0.019 & 30.31 & 0.498 & 0.334 & -0.455 & & & \\
\hline & $\begin{array}{l}\text { Even when I do not feel comfortable working with others, } \\
\text { I complete my duty. }\end{array}$ & 0.672 & 0.02 & 30.36 & 0.531 & 0.066 & -0.931 & & & \\
\hline & $\begin{array}{l}\text { I tend to sympathize with others' positions and feelings } \\
\text { in conflict situations. }\end{array}$ & 0.588 & 0.021 & 30.39 & 0.564 & -0.320 & -0.218 & & & \\
\hline \multirow{4}{*}{ Utilizing social resources } & $\begin{array}{l}\text { I have used career support services at school or outside to } \\
\text { solve career problems. }\end{array}$ & 0.318 & 0.024 & 10.86 & 0.788 & 0.716 & 0.161 & \multirow{4}{*}{0.718} & \multirow{4}{*}{0.963} & \multirow{4}{*}{0.944} \\
\hline & $\begin{array}{l}\text { I can ask others for useful information to make my career } \\
\text { decisions better. }\end{array}$ & 0.483 & 0.022 & 30.10 & 0.600 & -0.544 & 10.740 & & & \\
\hline & $\begin{array}{l}\text { I seek to receive practical feedback from a career mentor } \\
\text { on my career preparation process. }\end{array}$ & 0.785 & 0.022 & 20.66 & 0.786 & -0.066 & -0.451 & & & \\
\hline & $\begin{array}{l}\text { I ask those who are in the field of my interest, for } \\
\text { information and advice on career preparation. }\end{array}$ & 0.756 & 0.022 & 20.70 & 0.791 & -0.070 & -0.494 & & & \\
\hline
\end{tabular}

$\mathrm{a}=$ standardized estimates, $\mathrm{b}=$ error, $\mathrm{c}=$ mean, $\mathrm{d}=\mathrm{SD}, \mathrm{e}=$ skewness, $\mathrm{f}=$ kurtosis, $\mathrm{g}=$ Cronbach's $\alpha, \mathrm{h}=$ construct reliability, $\mathrm{i}=$ average variance extracted. 
Cronbach's alpha coefficient was calculated for each sub-factor to verify the reliability of the career adaptability scale for undergraduates (see Table 7). The internal consistency reliability of each sub-factor ranged from 0.654 to 0.845 , which is satisfactory. The reliability analysis showed that the questionnaire was thus developed has a reliable scale for measuring career adaptability.

Distributions of Participants and Measurements

The distribution of participants and items were examined according to the Rasch model, to simultaneously compare the distribution according to the level of career adaptability of the undergraduates and the difficulty of the items. In Figure 2, the left side of the distribution map in the figure is the participant distribution, the right side represents the items distribution, and " $\mathrm{M}$ " is the average estimate of the participant. The higher the value of the participant distribution, the higher the career adaptability. However, a high value of item distribution indicated that the participants had a low level of career adaptability.

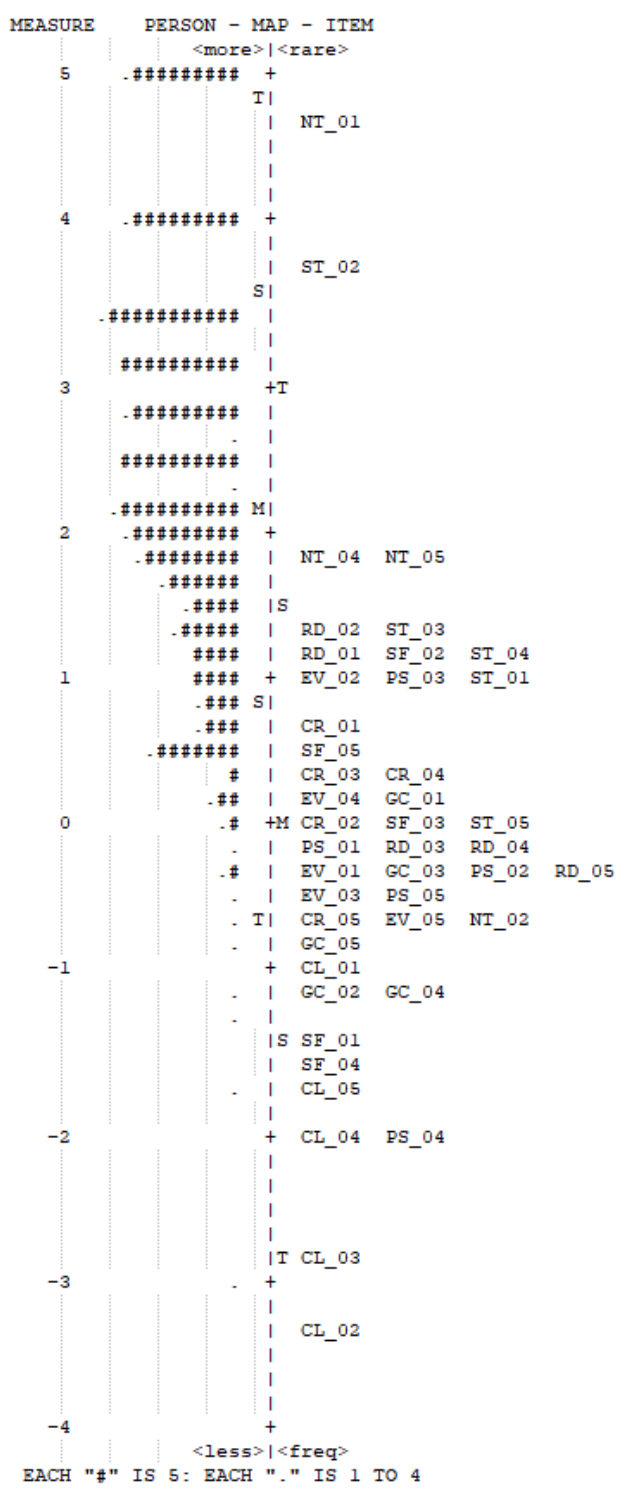

Figure 2. Participant and item estimates distribution.

Item NT01, "I have used career support services at school or outside to solve my career problems (career counseling center, job placement office, student counseling center, etc.)", yielded the most negative responses, while item CL02, a social responsibility factor 
that says, "I take responsibility for my job when working with others for a common task", received the most positive responses. Examining the area-specific distribution of all the items, those that corresponded to the ability to utilize social resources and the ability to cope with environmental stress (item ST02, "I seek for solutions to overcome career stress situations (employment counseling center, the Ministry of Employment and Labor, student counseling center, etc.)") were relatively low, while the items related to social responsibility (item CL02, "I take responsibility for my job when working with other for a common task"; item CL03, "I revise my opinion by listening to and considering others' perspectives and opinions"; item CL04, "I tend to sympathize with others' positions and feelings in conflict situations") and positive career beliefs (item PS04, "I can properly change my career path or job as needed") were relatively high. In other words, while students have a high level of social responsibility, their ability to collaborate with others, utilize social resources for career decisions, and their adaptation and ability to cope with environmental stress are relatively low.

\section{Discussion}

The purpose of this study was to develop and validate a career adaptability scale for undergraduates, considering future jobs and career developmental tasks. In this study, the need for career adaptability is identified, a clear definition of constructs enhancing the career adaptability of undergraduates is recognized, and a scale to explore and measure it for undergraduates is developed. In this section, the key findings and conclusions of the study are discussed.

In study 1 , the concept of the career adaptability of undergraduates was established, and a survey was conducted with career education experts to explore the constructs. As a result, the working definition of career adaptability was established as "the adaptability and self-controlling strategies to properly cope with career developmental tasks and future career challenges necessary for a successful career transition". Nine sub-factors were extracted across three categories to compose the items. These were divided into the following three areas: knowledge and recognition of the self and work environment, self-directed coping related to career behavior, and environmental interaction for career decisions and adaptation. The adaptive characteristics of individuals were categorized into the following nine factors: self-understanding to establish identity, searching for a work environment, positive career beliefs, coping with career-choice crisis, career preparation behavior, adjusting career goals, coping with environmental stress, socially responsible behavior, and utilizing social resources. The classification of these areas is based on the career development tasks of undergraduates. Specific information can be provided on the developmental tasks, in which the individual experiences difficulty when performing adaptive behavior. While conventional career adaptability scales of undergraduate students are developed to be valid in a general, broad cultural context $[10,13]$, it seems appropriate that educational interventions will be feasible, based on information about career development tasks, which present adaptive difficulties among individuals.

In study 2, the test was developed based on the results of the EFA and the item fit analysis using the Rasch model with the preliminary scale of career adaptability of undergraduates. The results using the Rasch model showed that seven items (i.e., "I seek to get practical feedback from a career mentor on my career preparation process" and six other items) were inappropriate for the scale. Based on the results of the item fit analysis and the validity verification of the items, a total of 45 items were selected. The EFA for this scale confirmed a structure of nine sub-factors.

In study 3, to evaluate the appropriateness of the career adaptability scale, (1) an item fit analysis of the items using the Rasch model and the distribution analysis of survey participants and question measurements; (2) CFA; and (3) a reliability test were conducted. The item fit analysis of the items using the Rasch model revealed that the goodness-of-fit was low for question NT03 (i.e., "I ask for others' support in changing my career plans (professors, parents, older friends, etc.)"). It was determined that there was a 
possibility that this question would overlap with the career goal adjustment in the area of the environmental interaction between career decisions and adaptation. A total of 44 items were finally selected, excluding question NT03 from the analysis, based on the judgment that the behavioral characteristics that this question measures are not clear, and it may correspond to one or more factors.

The distribution and calculation of measurements for each item using the Rasch model revealed that "the ability to utilize social resources" was the hardest to acquire. According to the analysis of the students' career adaptability level by item, the lowest level item was NT01, "I have used career support services at school or outside to solve career problems". In addition, the level was relatively low for items related to the ability to cope with environmental stress. These results provide useful information for developing career adaptability enhancement programs in the future, by highlighting the characteristics of students' career adaptability that are relatively difficult to improve. In other words, to improve career adaptability for undergraduates, and positively impact their career satisfaction and success, it is necessary to develop and disseminate educational programs that can improve the ability to interact with the environment and manage environmental stress. Meanwhile, the area of environmental interaction between career decisions and adaptation indicated a relatively high level of social responsibility. While the result reflects a high level of social responsibility in most undergraduates, further examination is necessary to conclude whether these results predict social responsibility in the job scene. Item PS04 ("I can switch my career path or job as needed"), related to the positive career beliefs factor, was relatively high, indicating a positive attitude towards the career transitions faced by undergraduates or professionals.

CFA, to check the factor structure of the final test tool, revealed that the hierarchical secondary factor model yielded a high level of goodness-of-fit. Therefore, it is valid for career adaptability to include the above nine factors across three domains. Career adaptability can be conceptualized in the areas of knowledge and recognition of the self and work environment, self-directed coping related to career behavior, and environmental interaction for career decisions and adaptation. In the area of knowledge and recognition of the self and work environment, the sub-factors included are self-understanding to establish identity, search for work environment, and positive career beliefs. In self-directed coping related to career behavior, the sub-factors are coping with career-choice crisis, career preparation behavior, and ability to coordinate career goals. In environmental interactions between career decisions and adaptation, the sub-factors are ability to cope with environmental stress, social responsibility, and ability to utilize social resources.

\subsection{Contribution and Implications}

The academic significance of this study is as follows. First, this study sought a new direction of career guidance at universities, by developing a tool that can objectively measure individual differences in the career adaptivity of South Korean undergraduate students. In an environment where the instability of career paths and occupations increases, career education in universities should show more concern and responsibility towards career development, without being limited to employment and the graduate school admittance of students. Thus, this study is significant in that the developed scale identifies individual differences in career adaptability and provides differentiated career guidance services according to the adaptability level. Second, while the existing career adaptability tests are intended to be valid in a broad cultural context, this study developed a scale that identifies adaptive factors that are required to perform career development tasks among South Korean undergraduates. This study is significant as an objective test, and was developed to measure career adaptability, considering the cultural background of South Korean undergraduates. Third, this study is significant as a scale with high diagnostic capability, and was developed by examining the goodness-of-fit test items by applying the Rasch model, in addition to factor analysis, which is a classic method of scale development. 
Based on the results of this study, the following strategies were proposed to use the diagnostic results of the career adaptability test of undergraduates within the South Korean context. First, the career adaptability test tool for South Korean undergraduate students can be used for student-tailored career guidance and counseling. This scale provides specific diagnostic information about where South Korean undergraduate students experience adaptive difficulties when performing career development tasks. Based on the results, students can self-diagnose vulnerable areas in career adaptability and establish plans for improvements. Second, based on the diagnostic results of this test, the instructor can identify the characteristics of the student group, and use them to select and organize the contents of the career education program. The instructor can determine priorities of the contents of education based on the diagnostic results of the student group, and reflect them to modify/supplement teaching and studying plans. Furthermore, this scale will be useful to career counselors when providing counseling or guidance to their counselees. Third, the attributes extracted as a result of the test can be used as basic data when the university develops a program that increases the career adaptability of undergraduate students.

\subsection{Limitations and Directions for Future Research}

The study has a few limitations, which need to be overcome to effectively apply the career adaptability characteristics found in this study to real-world education. First, since the number of items to evaluate students with high career adaptability were insufficient, it is necessary to revise the scale to develop more items with characteristics of high-level career adaptability. However, considering the fact that the purpose of the development of the career adaptability test is to screen students who have difficulties in career adaptability and to diagnose which areas they have difficulties in, it would be useful enough to diagnose students with a low level of career adaptability. For future studies, it appears to be necessary to develop items to measure a group of students with higher-level career adaptability, in order to distinguish the characteristics of career adaptability more accurately. Second, in this study, in order to determine the number of factors in the common factor model, the correlation matrix and scree plot were used. The common factors in this study were clear, so it was possible to determine the relatively clear number of factors using the scree plot. However, suggestions exist, such as judging the number of factors in the factor structure where the scree plot is not clear and tending to over-extract [45]. In addition, if the sample size is small, the scree plot may not be reliable due to the low sample stability, it is necessary to consider the use of parallel analysis [46], which is a more objective procedure than the scree plot [47]. Therefore, it seems necessary to compare the results of this study with the results of the parallel analysis in the procedure, to determine the number of factors for future studies. Third, although CFA, to check the factor structure of the final test tool, revealed that the hierarchical secondary factor model yielded a high level of goodness-of-fit, and item fit analysis of the items using the Rasch model was conducted to validate the developed scale, future studies should check the correlation with variables that may have positive effects on careers, such as life satisfaction and job satisfaction, to examine criterion validity. Furthermore, in this study, DIF (differential item functioning) was conducted according to gender, in order to verify the generalization validity of this test. For future research, it would be desirable to explore the items that have DIF according to groups such as grade, major, and school type, as well as gender. Fourth, this study was a cross-sectional study conducted at a certain time point and did not confirm whether the results would be supported over time. Therefore, future studies should be required to check whether the responses for a short-form scale, such as test-retest reliability, are maintained stably over time. Fifth, there is a limitation in generalizing the results of this study because it included a random sample of university students from a certain region of South Korea. The number of students in each major was not evenly distributed, so the possibility that the characteristics of the students in a particular major might have affected the study results cannot be ruled out. Therefore, it is necessary to verify whether the results of this study are consistent through follow-up studies in the future, considering various majors, years of 
study, and regions in the country. It will also be beneficial to verify whether the proposed scale is a reliable measurement tool that can be used regardless of the characteristics of the research participants. This may be conducted by verifying the response propensity and measurement invariance of the career adaptability scale according to the characteristics of the research participants (i.e., gender, year of study, major, etc.). Sixth, the test tool in this study is a total of 44 items of 9 factors, and some participants may feel fatigue and burden of taking the test. Therefore, in order to increase the usefulness of the career adaptability test, it would be desirable to develop a simple test in the future. In addition, it seems necessary to develop guidelines that can selectively utilize some factors of the test according to the judgment of instructors and counselors during career education and counseling.

\section{Conclusions}

This study developed a career adaptability scale measuring adaptive ability and selfcontrolling strategies to cope with career developmental tasks and future career tasks that are necessary for successful career transitions for undergraduates in Korea. For this purpose, three studies were conducted. In study 1, the career adaptability of South Korean undergraduate students was conceptualized, and sub-factors were explored, based on which a preliminary test was developed. In study 2 , a test was developed based on the results of item fit analysis using the Rasch model and the results of EFA to check the factor structure. In study 3 , the validity and reliability of the test tool were verified. Validity was confirmed for the test tool comprising 44 items across three domains (knowledge and recognition of the self and work environment, self-directed coping related to career behavior, and environmental interaction for career decisions and adaptation) and nine sub-factors (self-understanding to establish identity, search for work environment, positive career beliefs, coping with career-choice crisis, career preparation behavior, ability to coordinate career goals, ability to cope with environmental stress, social responsibility, and ability to utilize social resources), to measure career adaptability among South Korean undergraduate students.

Funding: This work was supported by the Ministry of Education of the Republic of Korea and the National Research Foundation of Korea (NRF-2020S1A5A8042232).

Institutional Review Board Statement: The study was conducted according to the guidelines of the Declaration of Helsinki, and approved by the Institutional Review Board of Dankook Universiry (2021-04-020).

Informed Consent Statement: Informed consent was obtained from all subjects involved in the study.

Data Availability Statement: The raw data supporting the conclusions of this article will be made available by the authors, without undue reservation.

Conflicts of Interest: The author declares that the research was conducted in the absence of any commercial or financial relationships that could be construed as a potential conflict of interest.

\section{References}

1. Hartung, P.J.; Porfeli, E.J.; Vondracek, F.W. Career adaptability in childhood. Career Dev. Q. 2008, 57, 63-74. [CrossRef]

2. Chan, S.H.J.; Mai, X. The relation of career adaptability to satisfaction and turnover intentions. J. Vocat. Behav. 2015, 89, 130-139. [CrossRef]

3. Johnston, C.S.; Maggiori, C.; Rossier, J. Professional trajectories, individual characteristics, and staying satisfied and healthy. J. Career Dev. 2016, 43, 81-98. [CrossRef]

4. Hartung, P.J.; Cadaret, M.C. Career adaptability: Changing self and situation for satisfaction and success. In Psychology of Career Adaptability, Employability and Resilience; Maree, J.G., Ed.; Springer: New York, NY, USA, 2017; pp. 15-28.

5. Savickas, M.L. The theory and practice of career construction. In Career Development and Counseling: Putting Theory and Research to Work; Brown, S.D., Lent, R.T., Eds.; John Wiley \& Sons: Hoboken, NJ, USA, 2005; pp. 42-70.

6. Super, D.E.; Knasel, E.G. Career development in adulthood: Some theoretical problems and a possible solution. Br. J. Guid. Counc. 1981, 9, 194-201. [CrossRef] 
7. Savickas, M.L. Career construction: A developmental theory of vocational behavior. In Career Choice and Development; Brown, D., Ed.; Jossey-Bass: San Francisco, CA, USA, 2002; pp. 149-205.

8. Savickas, M.L. Career construction theory and practice. In Career Development and Counseling: Putting Theory and Research into Work, 2nd ed.; Lent, R.W., Brown, S.D., Eds.; John Wiley \& Sons: Hoboken, NJ, USA, 2013; pp. 147-183.

9. Savickas, M.L.; Nota, L.; Rossier, J.; Dauwalder, J.P.; Duarte, M.E.; Guichard, J.; Van Vianen, A.E. Life designing: A paradigm for career construction in the 21st century. J. Vocat. Behav. 2009, 75, 239-250. [CrossRef]

10. Savickas, M.L.; Porfeli, E.J. Career adapt-abilities scale: Construction, reliability, and measurement equivalence across 13 countries. J. Vocat. Behav. 2012, 80, 661-673. [CrossRef]

11. Jang, K.Y.; Kim, B.W. The development of the career adaptability scale for the Korean university students. Korean J. Counsel. 2011, 12, 539-558. [CrossRef]

12. Rottinghaus, P.J.; Day, S.X.; Borgen, F.H. The career futures inventory: A measure of career-related adaptability and optimism. J. Career Assess. 2005, 13, 3-24. [CrossRef]

13. Choi, O.H.; Kim, B.H. Career Optimism and Adaptability of the College Students: The Korean Validation Study of the Career Futures Inventory (CFI). Korean J. Counsel. 2006, 7, 821-833.

14. Nota, L.; Ginevra, M.C.; Soresi, S. The career and work adaptability questionnaire (CWAQ): A first contribution to its validation. J. Adolesc. 2012, 35, 1557-1569. [CrossRef]

15. Hirschi, A. Career adaptability development in adolescence: Multiple predictors and effect on sense of power and life satisfaction. J. Vocat. Behav. 2009, 74, 145-155. [CrossRef]

16. Creed, P.A.; Fallon, T.; Hood, M. The relationship between career adaptability, person and situation variables, and career concerns in young adults. J. Vocat. Behav. 2009, 74, 219-229. [CrossRef]

17. Goodman, J. Career adaptability in adults: A construct whose time has come. Career. Dev. Q. 1994, 43, 74-84. [CrossRef]

18. Pratzner, F.C.; Ashley, W.L. Occupational adaptability and transferable skills: Preparing today's adults for tomorrow's education. In Yearbook of the American Vocational Association; American Vocational Association, Ed.; American Vocational Association: Arlington, TX, USA, 1984.

19. Tak, J. Career adapt-abilities scale-Korea form: Psychometric properties and construct validity. J. Vocat. Behav. 2012, 80, 712-715. [CrossRef]

20. Savickas, M.L. Measuring career development: Current status and future directions. Career Dev. Q. 1994, 43, 54-62. [CrossRef]

21. Fouad, N.A. Work and vocational psychology: Theory, research, and applications. Annu. Rev. Psychol. 2007, 58, 543-564. [CrossRef] [PubMed]

22. Krieshok, T.S.; Black, M.D.; McKay, R.A. Career decision making: The limits of rationality and the abundance of non-conscious processes. J. Vocat. Behav. 2009, 75, 275-290. [CrossRef]

23. Savickas, M.L.; Porfeli, E.J. Revision of the career maturity inventory: The adaptability form. J. Career Assess. 2011, 19, 355-374. [CrossRef]

24. Maggiori, C.; Rossier, J.; Savickas, M.L. Career adapt-abilities scale-short form (CAAS-SF) construction and validation. J. Career Assess. 2017, 25, 312-325. [CrossRef]

25. Rottinghaus, P.J.; Buelow, K.L.; Matyja, A.; Schneider, M.R. The career futures inventory-revised: Measuring dimensions of career adaptability. J. Career Assess. 2012, 20, 123-139. [CrossRef]

26. Rottinghaus, P.J.; Eshelman, A.; Gore, J.S.; Keller, K.J.; Schneider, M.; Harris, K.L. Measuring change in career counseling: Validation of the Career Futures Inventory-Revised. Int. J. Educ. Vocat. Guid. 2017, 17, 61-75. [CrossRef]

27. Pulakos, E.D.; Arad, S.; Donovan, M.A.; Plamondon, K.E. Adaptability in the workplace: Development of a taxonomy of adaptive performance. J. Appl. Psychol. 2000, 85, 612-624. [CrossRef]

28. Zhang, W.; Xu, Y.; Peng, L.; Bian, C.; Yu, Y.; Li, Y.; Li, M. Military career adaptability questionnaire in China: Development and validation. Front. Psychol. 2020, 11, 280. [CrossRef]

29. Havighurst, R.J. Social and psychological needs of the aging. Ann. Am. Acad. Political Soc. Sci. 1952, 279, 11-17. [CrossRef]

30. Ginzberg, E. Toward a theory of occupational choice. Occup. Vocat. Guid. J. 1952, 30, 491-494. [CrossRef]

31. Super, D.E. A life-span, life-space approach to career development. In Career Choice and Development: Applying Contemporary Theories to Practice, 2nd ed.; Brown, D., Brooks, L., Eds.; Jossey-Bass: San Francisco, CA, USA, 1990.

32. Lee, H.K.; Choi, Y.K. Analysis of the educational needs of university job center career consultants based on career development task of university students. Korean J. Vocat. Edu. Res. 2019, 38, 43-64. [CrossRef]

33. Brown, F.W.; Bryant, S.E.; Reilly, M.D. Does emotional intelligence-as measured by the EQI-influence transformational leadership and/or desirable outcomes? J. Leadersh. Organ. Devel. 2006, 27, 330-351. [CrossRef]

34. Linacre, J.M. WINSTEPS Rasch Measurement; Version 4.7.1; Computer Software; WINSTEPS \& Facets: Chicago, IL, USA, 2021; Available online: http:/ / www.Winsteps.com (accessed on 1 May 2021).

35. Lunz, M.E.; Stahl, J.; Wright, B.D. The invariance of rater severity calibration. In Objective Measurement: Theory into Practice; Engelhard, G., Wilson, M., Eds.; Ablex Publishing: Morwood, NJ, USA, 1996; Volume 3, pp. 99-112.

36. Boone, W.J.; Staver, J.R.; Yale, M.S. Rasch Analysis in the Human Sciences; Springer: Berlin, Germany, $2014 ;$ pp. $217-234$.

37. Linacre, J.M. Local independence and residual covariance: A study of Olympic figure skating ratings. J. Appl. Meas. 2009, 10, 157-169. [PubMed]

38. Raiche, G. Critical eigenvalue sizes in standardized residual principal components analysis. Rasch Meas. Trans. 2005, 19, 1012. 
39. Wolfe, E.W.; Smith, E.V., Jr. Instrument development tools and activities for measure validation using Rasch models: Part II-validation activities. J. Appl. Meas. 2007, 8, 204-234. [PubMed]

40. Snedecor, G.W.; Cochran, W.G. Statistical Methods, 7th ed.; Iowa State University Press: Ames, IA, USA, 1980.

41. Williams, B.; Onsman, A.; Brown, T. Exploratory factor analysis: A five-step guide for novices. Australas. J. Paramed. 2010, 8, 1-13. [CrossRef]

42. Costello, A.B.; Osborne, J. Best practices in exploratory factor analysis: Four recommendations for getting the most from your analysis. Pract. Assess. Res. Eval. 2005, 10,1-9.

43. Gorsuch, R.L.; Venable, G.D. Development of an “age universal” IE scale. J. Sci. Study Relig. 1983, 22, 181-187. [CrossRef]

44. Fornell, C.; Larcker, D.F. Evaluating structural equation models with unobservable variables and measurement error. J. Mark. Res. 1981, 18, 39-50. [CrossRef]

45. Zwick, W.R.; Velicer, W.F. Comparison of five rules for determining the number of components to retain. Psychol. Bull. 1986, 99, 432-442. [CrossRef]

46. Horn, J.L. A rationale and test for the number of factors in factor analysis. Psychometrika 1956, 30, 179-185. [CrossRef] [PubMed]

47. Fabrigar, L.R.; Wegener, D.T.; MacCallum, R.C.; Strahan, E.J. Evaluating the use of exploratory factor analysis in psychological research. Psychol. Methods 1999, 4, 272-299. [CrossRef] 